\title{
1 Engineered Jute Bags for Storing Food Grains within Harrington's Safe \\ Zone of Seed Moisture Content
}

\author{
Kennedy Odokonyero, Adair Gallo Jr., and Himanshu Mishra ${ }^{*}$
}

\author{
Water Desalination and Reuse Center, Division of Biological and Environmental Sciences and \\ Engineering, King Abdullah University of Science and Technology (KAUST), \\ Thuwal 23955 - 6900 Saudi Arabia, \\ Emails Addresses: kennedy.odokonyero@kaust.edu.sa; adair.gallojunior@kaust.edu.sa; \\ himanshu.mishra@kaust.edu.sa \\ *Corresponding Author: himanshu.mishra@kaust.edu.sa
}

\section{Abstract}

Harrington's thumb rule states that for every $1 \%$ increase in seed moisture content (SMC), seed lifetime decreases by $\leq 50 \%$. Thus, to avoid post-harvest grain losses, stored seeds must be insulated from water. Although the jute bags typically used to store grains afford an ecofriendly, durable, and low-cost storage solution, their hydrophilic nature makes them vulnerable to wetting from airborne humidity and precipitation events. To address this issue, we treated jute fabrics with alkali and wax to render them water-repellent. A 2-month seed storage experiment revealed that wax-coated jute bags (WCJBs) outperformed control jute bags (CJBs) at safeguarding wheat (Triticum aestivum) grains exposed to 55\%-98\% relative humidity. Specifically, grains stored in WCJBs exhibited $15 \%-50 \%$ less SMC than grains stored in CJBs, which led to a $21 \%-66 \%$ enhancement in the germination efficacy of WCJB-stored seeds. This engineering solution could enhance the potential of jute bags to reduce post-harvest losses. 
24 Keywords: Harrington's rule; seed storage; post-harvest losses; jute bags; biomimetics; relative

25 humidity; seed germination; Triticum aestivum.

26

27 


\section{INTRODUCTION}

In 2020, the Nobel Peace Prize was awarded to the World Food Programme; this is a testimony to the complete dependence of humans on our food supply ${ }^{1}$. According to the United

31 Nation's Food and Agricultural Organization, developing sustainable agricultural practices that can feed $\sim 10^{10}$ humans in 2050 is the mega-challenge of our time ${ }^{2-4}$. To meet the increasing

33 demand for food, annual global food production must increase by around $70 \% \%^{5}$. Grain crops, such as cereals, oil seeds, and pulses, form the basis of global food security ${ }^{6-8}$, with two billion tons of grains currently produced annually ${ }^{7,9}$. By 2050, global grain production is projected to increase by $>33 \%$ to meet food and animal feed needs ${ }^{3,10}$. Increasing crop yields beyond current

37 levels is likely to be difficult given the effects of climate change, deforestation, rising 38 groundwater depletion, and overstressed energy resources ${ }^{11-14}$. This emerging food security scenario will demand a highly efficient food supply chain from farms to consumption ${ }^{8}$.

At present, $\sim 25 \%-33 \%$ of the total grain produced annually is lost between harvest and consumption through "post-harvest losses" (PHLs) ${ }^{6,15}$, which entail quantitative and qualitative

42 food losses within the interconnected post-harvest chain from harvest through to storage, 43 processing, marketing, and finally consumption ${ }^{16-18}$. Alarmingly, in developing countries, up to $4450 \%-60 \%$ of cereals may be lost during storage due to poor storage infrastructure ${ }^{16-18}$, slower 45 adoption of modern technologies ${ }^{19}$, and fragmented information sharing ${ }^{20}$. Conversely, in 46 developed countries, grain losses can be as low as $1 \%-2 \%$ because of better post-harvest 47 handling and improved hermetic storage technologies ${ }^{9,20}$. Nevertheless, total food waste at the consumer level in developed countries is $>40 \%$ ( 222 million tons); thus, the magnitude of food

49 losses in these countries is comparable to that in developing countries and similar to the net food 50 production of sub-Saharan Africa ( 230 million tons $)^{6}$. PHLs can be in form of spoilage, seed 
51 viability loss, grain depletion, and nutritional $\operatorname{loss}^{21}$ resulting from biotic (e.g., insects, rodents, 52 and fungi) or abiotic (e.g., temperature and air-moisture/humidity) factors ${ }^{9}$. Fungal infection and 53 mycotoxin contamination are major causes of PHL during seed/grain/cereal storage, accounting 54 for $25 \%-40 \%$ of $\operatorname{losses}^{22}$.

In the context of seed deterioration, Harrington's thumb rule states that for every $1 \%$

56 increase in seed moisture content (SMC), the storage life of the seed is reduced by half ${ }^{23-24}$. This

57 empirical rule underscores the importance of insulating stored grains from water in liquid and

58 vapor forms. Typically, seeds are dried to achieve a SMC of $\sim 13 \%$ before storage ${ }^{15-16}$; when

59 SMC reaches $\sim 16 \%$, Harrington's rule becomes relevant and seeds begin to deteriorate in an

60 accelerated manner ${ }^{23}$. Therefore, to avoid increased SMC, it is important to carefully consider

61 storage structures, packaging materials, storage duration, and relative humidity (RH). ${ }^{15}$ Issues

62 arise when moisture-absorbing storage bags facilitate the diffusion of moisture to dry grains and

63 thereby increase SMC. In developing countries, including those in the Indian subcontinent and

64 sub-Saharan Africa, farmers exploit jute bags for grain storage because of their low-cost,

65 mechanical durability, and traditional usage over millenia $9,19,25$. However, jute is hydrophilic

66 and therefore absorbs water due to its chemical components, which include cellulose $(\sim 60 \%)$,

67 hemicellulose $(\sim 20)$, lignin $(\sim 10 \%)$, pectin, and water-soluble substances ${ }^{26-28}$. Consequently, jute

68 bags are vulnerable to environmental water, e.g., precipitation, $\mathrm{RH}$, and soil moisture, which

69 interacts with conventional storage systems. Indeed, water accumulation and/or vapor transport

70 through jute bags increases SMC and causes fungal infections; the resultant seed deterioration

71 affects seed germination capacity $^{29-31}$. In India, about $60 \%-70 \%$ of grains are stored in

72 traditional structures in which $36.0 \%$ and $33.5 \%$ of total PHLs are encountered for rice and

73 wheat, respectively ${ }^{32}$. In sub-Saharan Africa, PHLs of 59\% are estimated for maize grains after a 
7490 -day storage period in traditional storage structures (granary/polypropylene bags) ${ }^{33}$. Thus, low-

75 cost surface modifications that create water-repellant jute bags are required to reduce PHLs

76 during storage.

77 To address this problem, we took inspiration from the numerous plants and animals that 78 have developed water-repellency by combining hydrophobic waxy coatings with 79 micro/nanoscale surface roughness. Examples include lotus leaves (Nelumbo nucifera) $)^{34}$, the 80 bodies of sea-skaters (Halobates germanus) ${ }^{35-36}$, the cuticles of springtails (Collembola) $)^{37}$, as 81 well as certain desert plants ${ }^{38}$ and insects ${ }^{39}$ among others ${ }^{40}$. Researchers have already developed 82 bioinspired technologies for drag reduction ${ }^{41}$, separation and purification ${ }^{42-43}$, cavitation 83 mitigation ${ }^{44}$, coating-free entrapment of air underwater ${ }^{37,42,45}$, and producing super-water84 repellent $\operatorname{cotton}^{46}$. Thus, there is a growing expectation for new agrotechnologies to be inspired 85 by nature ${ }^{47-48}$.

86 Herein, we present a bioinspired surface treatment for jute bags that enhances their

87 robustness for improved grain storage. Specifically, jute fabrics were treated with alkalis and 88 then coated with paraffin wax to produce water repellence. The seed storage efficacy of these 89 wax-coated jute bags (WCJBs) was compared with that of control jute bags (CJBs, i.e., untreated 90 jute bags) under controlled humidity conditions during a 2-month storage experiment. This was

91 followed by a germination study in which the viability of seeds stored in WCJBs and CJBs was

92 comparably assessed. The low cost, eco-friendly, and simple treatment process reported here has

93 the potential to substantially reduce PHLs, particularly in developing countries currently reliant 94 on regular jute bags for grain storage. 
MATERIAL AND METHODS

Materials and apparatus. Paraffin wax was obtained from common white candles manufactured by IKEA (Sweden); hexane and ethanol were purchased from VWR International S.A.S (Fontenay-Sous-Bois, France); ammonium acetate, glacial acetic acid, and calcium nitrate tetrahydrate $\left(\mathrm{Ca}\left(\mathrm{NO}_{3}\right)_{2} \cdot 4 \mathrm{H}_{2} \mathrm{O}\right)$ were purchased from Sigma Aldrich (St. Louis, MO, USA); sodium chloride, potassium sulfate, and sodium hydroxide were purchased from Fisher Scientific (New Jersey, USA). All chemicals were used as received from suppliers. Jute 104 packaging sacks (Indian Sela Basmati Rice, $50 \mathrm{~kg}$ ) were obtained from the Al Jawahir Company 105 (Saudi Arabia). A Quanta 600 scanning electron microscope system was used for scanning electron microscopy. A Quorum Q150 TS sputter coater was used to coat jute bags (CJBs and WCJBs) with a $3 \mathrm{~nm}$-thick platinum layer to avoid electrical charging during electron microscopy. A DSA100E contact angle goniometer (Kruss, Germany) was used to characterize the wettability of surfaces. Wheat grains (T. aestivum L.) were harvested from a field at King Abdulaziz University's Agricultural Research Station in Hada Al-Sham (which extends between $39^{\circ} 30^{\prime}$ and $40^{\circ} 15^{\prime}$ East and $21^{\circ} 45^{\prime}$ and $22^{\circ} 10^{\prime}$ North, in Makkah, Saudi Arabia).

112 Surface treatment of jute. Jute sacks were cut into $14 \times 7 \mathrm{~cm}$ pieces and hand-sewn to produce 113 jute storage bags. First, the bags were cleaned by immersion in water (10 min) and then $70 \%$ 114 ethanol $(20 \mathrm{~min})$, before being dried in a thermal convection oven at $80^{\circ} \mathrm{C}(30 \mathrm{~min})$. Cleaned 115 bags were then immersed in $0.5-\mathrm{M}$ ammonium acetate solution (adjusted to $\mathrm{pH} 5$ using $1.0 \%$ 116 glacial acetic acid) for $30 \mathrm{~min}$. After further oven-drying at $80^{\circ} \mathrm{C}(30 \mathrm{~min})$, the bags were 117 immersed in 5\% (m/v) $\mathrm{NaOH}$ solution $(1.25 \mathrm{M}$ and $\mathrm{pH} \sim 14)$ for $2 \mathrm{~h}$. These alkali-treated bags 118 were washed with deionized water and again oven-dried at $80^{\circ} \mathrm{C}$ (30 min). Subsequently, the 119 bags were immersed in solutions of paraffin wax dissolved in hexane $(6 \mathrm{~g} / \mathrm{L})$, during which they 
120 were turned upside-down several times to facilitate uniform coating. After 30 min of this treatment, the bags were left to dry overnight in a solvent hood at $21.6^{\circ} \mathrm{C} \pm 0.5^{\circ} \mathrm{C}$.

122 Wettability tests. Deionized water droplets with and without food coloring and the DSA100E 123 contact angle goniometer were used to characterize the wettability of bag surfaces. WCJBs and 124 CJBs were also exposed to simulated rainfall for $\sim 1 \mathrm{~min}$ : they were placed at an angle of $\sim 30^{\circ}$ 125 and the simulated raindrops were applied by releasing water droplets $(\sim 2 \mathrm{~mL})$ from a syringe 126 placed $\sim 5 \mathrm{~cm}$ above the bags. The moisture absorption of WCJBs and CJBs was estimated by 127 measuring their mass.

128 Seed storage experiments. Clean and healthy $T$. aestivum grains, devoid of any physical 129 damage, were selected and placed inside paper bags for initial weight measurement. These grains 130 were then dried in an oven at $80^{\circ} \mathrm{C}$ for $72 \mathrm{~h}$, after which their mass did not change further; thus, $131 \mathrm{SMC}$ in the initial state was calculated as follows: $S M C=\left(W_{1}-W_{2}\right) / W_{1}$, where $W_{1}$ is the 132 initial weight of grains and $W_{2}$ is their final weight after drying. Subsequently, wheat grains were 133 packaged in WCJBs and CJBs, and the bags were placed in airtight plastic containers with the 134 following RHs: 55\%, 75\%, and 98\%. The air humidity level was controlled in confined spaces 135 by equilibrating it with supersaturated salt solutions of $\mathrm{Ca}\left(\mathrm{NO}_{3}\right)_{2} \cdot 4 \mathrm{H}_{2} \mathrm{O}, \mathrm{NaCl}$, and $\mathrm{K}_{2} \mathrm{SO}_{4}{ }^{49-50}$. 136 Specifically, to obtain $55 \% \mathrm{RH}, 50 \mathrm{~g}$ of $\mathrm{Ca}\left(\mathrm{NO}_{3}\right)_{2} \cdot 4 \mathrm{H}_{2} \mathrm{O}$ was dissolved in $100 \mathrm{~mL}$ of deionized 137 water by stirring; more salt was added until a saturated solution was formed with a salt:water 138 ratio of $3: 1(\mathrm{w} / \mathrm{w})$. This procedure was repeated to obtain $75 \% \mathrm{RH}$ using $\mathrm{NaCl}$ (but with a $2: 1$ 139 salt:water ratio) and 98\% $\mathrm{RH}$ using $\mathrm{K}_{2} \mathrm{SO}_{4}$ (at a $\sim 3: 1$ salt:water ratio). The saturated salt 140 solutions were then poured into the lower compartment of the airtight plastic containers, which 141 were integrated with humidity and temperature sensors (Fig. 1). The bags containing wheat 142 grains were then placed on a plastic mesh tray (barrier) above the saturated salt solutions; 
143 therefore, they were exposed to air with well-controlled humidity. Experiments were carried out

144 in triplicate; therefore, nine containers with WCJBs or CJBs were randomly placed and

145 monitored for 2 months. Moisture absorption was determined by weighing each jute bag every 3

146 days. Total moisture absorbed was calculated in grams per gram of jute bag plus stored seed

147 combined.
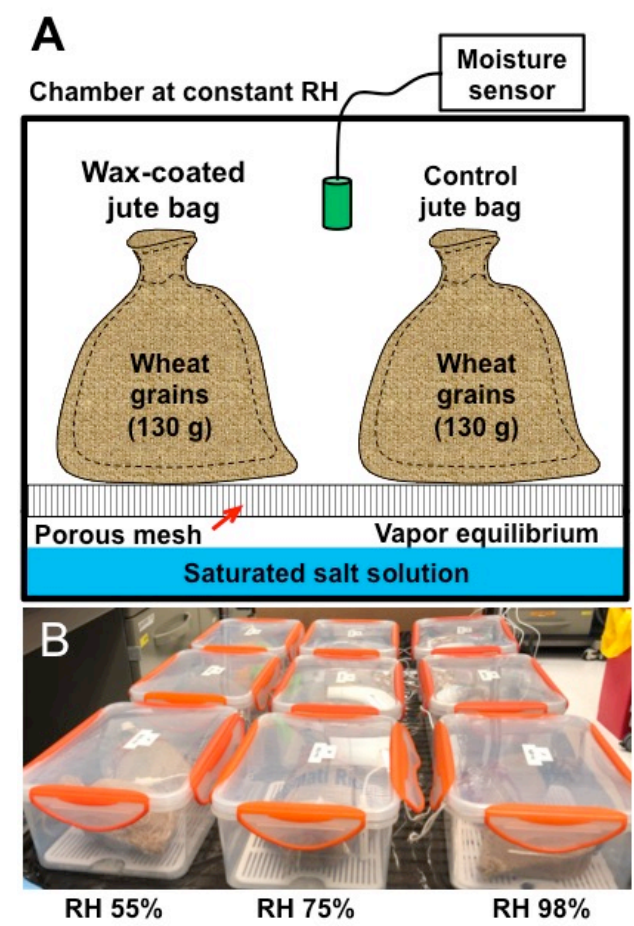

149 Figure 1 Moisture absorption setup for wheat grains stored in jute bags under variable relative 150 humidity (RH) conditions. (A) Schematic of a moisture box containing one control jute bag 151 (CJB) and one wax-coated jute bag (WCJB) in each storage chamber. Each bag contained $130 \mathrm{~g}$ 152 of oven-dried wheat grains. The saturated salt solution at the bottom of the box allowed for 153 precise control of air RH. (B) Photograph of the experimental setup showing the three different $154 \mathrm{RH}$ conditions $(50 \%, 75 \%$ and $98 \% \mathrm{RH})$ replicated in triplicate.

156 Seed moisture content and post-storage germination/viability. After two months of seed 157 storage, seed groups were combined based on RH treatment during storage. From these larger 158 groups, $\sim 130 \mathrm{~g}$ of seeds was withdrawn into paper bags, weighed, and then oven-dried at $80^{\circ} \mathrm{C}$ 
159 for $72 \mathrm{~h}$ to determine post-storage SMC. To evaluate the germination viability of post-storage 160 seeds, 30 seeds from each storage bag were germinated in Petri dishes containing Whatman filter

161 paper soaked in deionized water. These dishes were maintained in a dark incubator and allowed

162 to germinate at $21.6^{\circ} \mathrm{C} \pm 0.5^{\circ} \mathrm{C}$. The germination patterns of seeds were monitored from the first 163 day after sowing until the seventh day, after which the experiment was discontinued.

164 Statistical analysis. The seed storage experiment involved a completely randomized factorial 165 design, which was used to investigate the effect of jute storage bags and $\mathrm{RH}$ on moisture 166 absorption, SMC, and seed germination percentage. For analysis of data including triplicate 167 samples per treatment, we used Origin Pro software to perform a two-way ANOVA, with 168 Tukey's test applied for multiple comparisons of means; $p<0.05$ was set as the level of 169 statistical significance ${ }^{51}$.

\section{RESULTS AND DISCUSSION}

172 Water repellency. Alkali treatment of cellulosic fibers, also known as mercerization, has been 173 exploited to tune various characteristics, such as elastic moduli, brittleness, surface roughness, 174 and readiness for surface coating, of jute and $\operatorname{cotton}^{27,46,52-54}$. In the current study, the alkali 175 treatment (Fig. 2) of jute enhanced the surface roughness of fibers, presumably due to the 176 dissolution of the hemicellulose content (Fig. 3). Previously, alkali treatment has been reported 177 to dissolve hemicellulose and other fiber components, thereby rearranging them, which results in 178 the swelling and constriction of pores in jute fabrics ${ }^{27,55-57}$. 


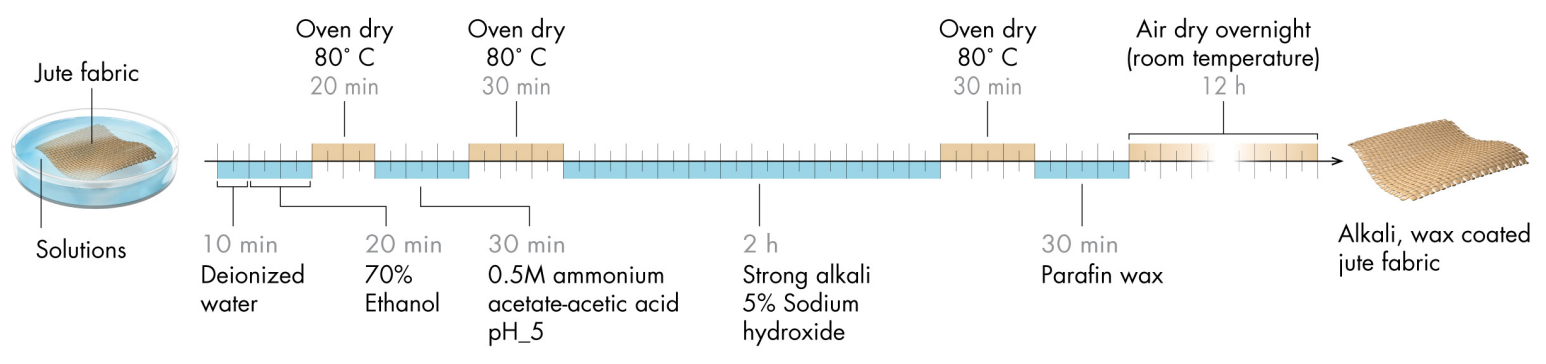

180 Figure 2. Schematic of the jute surface treatment process (Credit: Xavier Pita, KAUST).

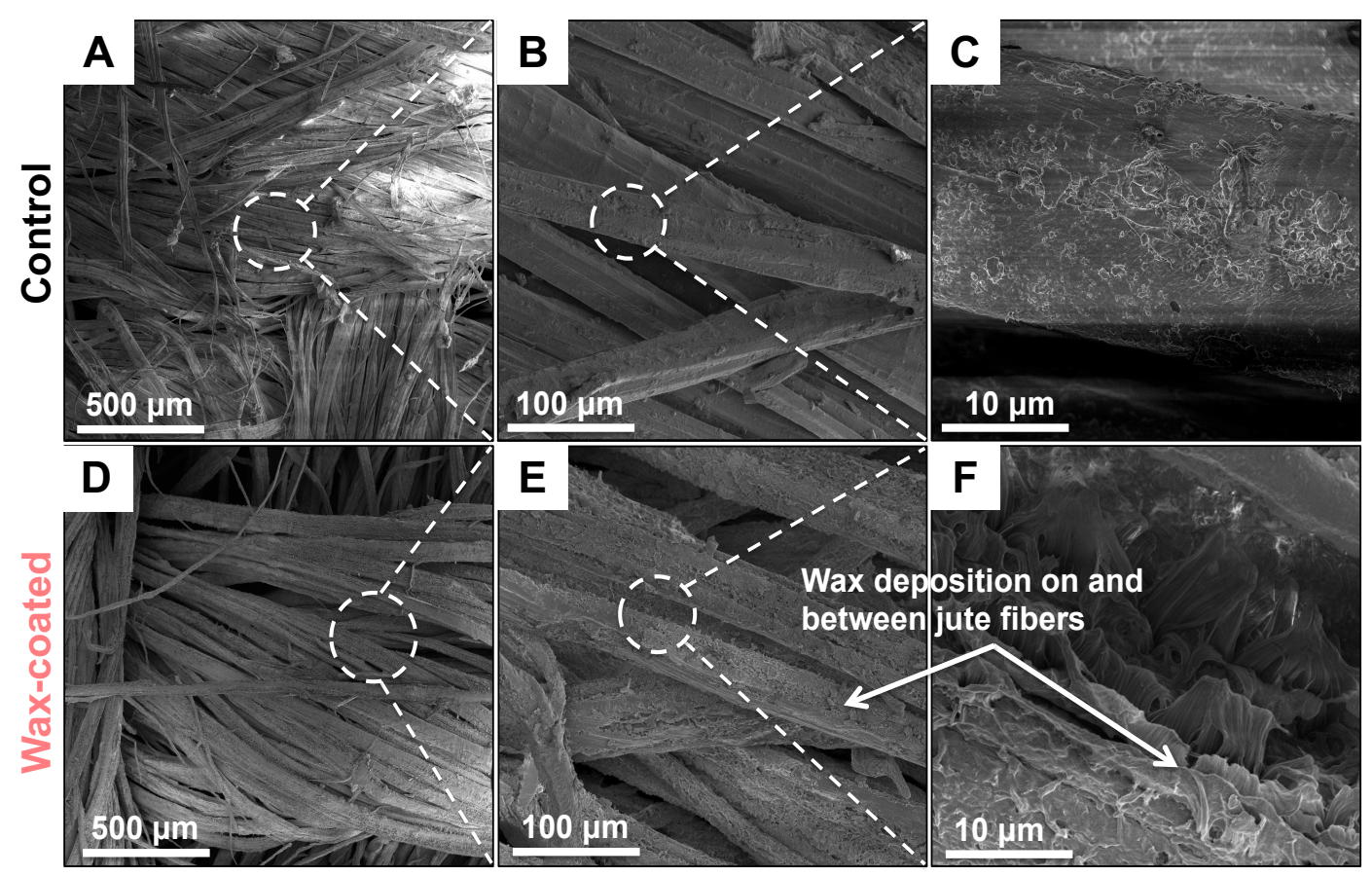

183 Figure 3. Representative scanning electron micrographs of jute fiber surface morphologies from 184 control jute bags (CJBs) and wax-coated jute bags (WCJBs). Fibers from CJBs (A, B, and C) 185 show lower surface roughness in comparison to WCJB fibers (D, E, and F). Wax deposits are 186 also indicated with arrows.

We chose an alkali concentration of $5 \%$ and treatment duration of $2 \mathrm{~h}$ because they enhance the surface roughness of fibers without significantly depleting their mechanical 
190 strength $^{27,55}$. For instance, Wang et al. ${ }^{58}$ demonstrated that mechanical properties, such as tensile 191 strength, flexural strength, tensile modulus, and flexural modulus, were superior for $6 \% \mathrm{NaOH}-$ 192 treated jute fabric reinforced composites relative to the mechanical properties of jute fabrics 193 treated at higher alkali concentrations $(>6 \%)$. High alkali concentrations not only remove lignin 194 and hemicellulose but also change the native cellulose I to cellulose $\mathrm{II}^{27,59}$. Such concentrations 195 can also cause excessive peeling of the fiber surface, which reduces the strength and toughness 196 of fibers ${ }^{58}$. In our further analyses, as the alkali-treated fabrics were coated with paraffin wax, the 197 combination of surface roughness and the hydrophobicity of the wax produced robust water 198 repellence ${ }^{43,60}$. The intrinsic hydrophobicity of the paraffin wax is characterized by the apparent 199 contact angles of water droplets on smooth wax-coated surfaces: $\theta_{o} \approx 105^{\circ}$. When a rough 200 surface is coated with a hydrophobic coating, the resulting water-repellence is enhanced by the 201 entrapment of air inside the surface asperities, which also prevent the penetration of water into 202 the microtexture. After wax coating, the gaps between the WCJB fibers reduced in comparison to 203 the gaps between the CJB fibers (Fig. 3A-C).

204 When water droplets of $\sim 8 \mu \mathrm{L}$ were placed onto CJBs, they gradually penetrated into the 205 fibers in $\leq 2 \mathrm{~min}$ (Figure 4A, C, and E). In contrast, this volume of water droplets placed onto 206 WCJBs did not penetrate into the fibers due to the entrapment of air in the microtexture; the 207 drops exhibited apparent contact angles of $\theta_{\mathrm{r}} \approx 130^{\circ}$ and remained in their sessile position 208 (pinned and $\theta_{\mathrm{r}}$ decreasing) until they evaporated (Figure 4B, D, and F). These air-trapped 209 wetting states are described by the Cassie-Baxter model ${ }^{61}$, which connects the macroscopic 210 apparent contact angles on the rough surface, $\theta_{\mathrm{r}}$, with $\theta_{\mathrm{o}}$ and the area fractions of liquid-solid $211\left(\phi_{\mathrm{LS}}\right)$ and liquid-vapor $\left(\phi_{\mathrm{LV}}\right)$ fractions underneath the drop as $\cos \theta_{\mathrm{r}}=\phi_{\mathrm{LS}} \times \cos \theta_{o}-\phi_{\mathrm{LV}}$. 


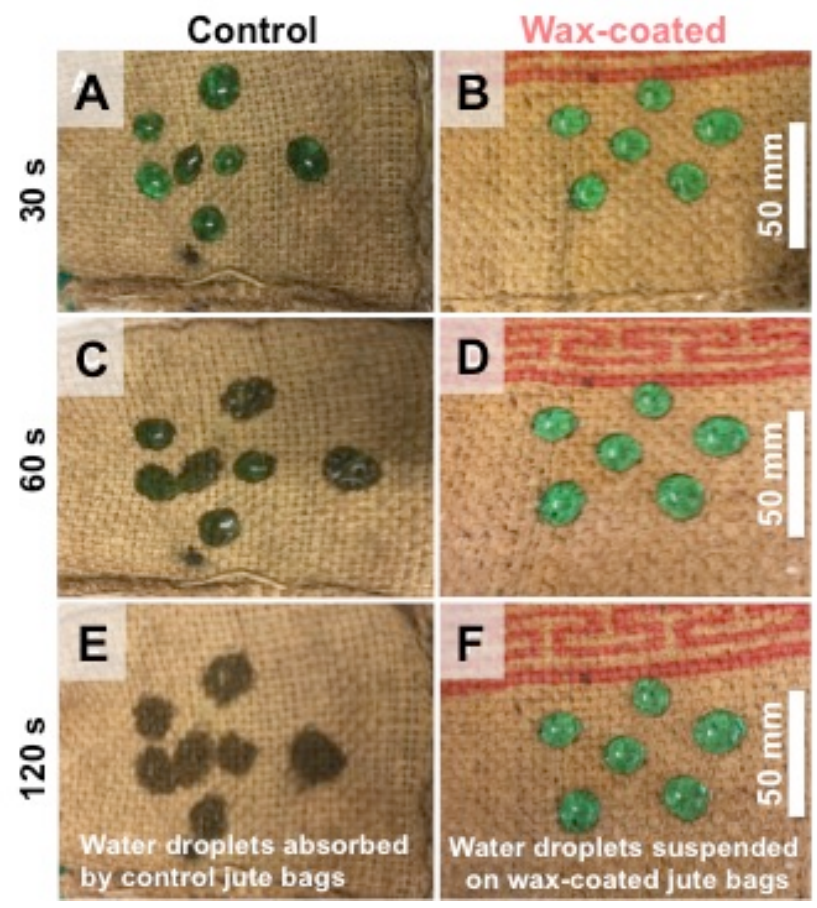

213 Figure 4. Photographic images of the time-dependent wetting of a control jute bag (CJB) and 214 wax-coated jute bag (WCJB) with colored water droplets placed on the jute surfaces. At $30 \mathrm{~s}$, the 215 water droplets began to rapidly seep through the CJB, whereas the droplets remained suspended 216 on the WCJB (A and B). In only $1 \mathrm{~min}$, the CJB showed significant wetting; in contrast, the 217 water droplets remained stable on the WCJB (C and D). From 2 min onwards, the water droplets 218 were completely absorbed by the CJB, whereas the droplets on the WCJB were stable and 219 remained standing for $>3 \mathrm{~h}(\mathbf{E}$ and $\mathbf{F})$.

222 the impact of water droplets, which they accumulated (Movie 1); however, the simulated 223 raindrops simply rolled-off the WCJBs, thereby preventing water accumulation (Movie 2). In 224 comparison to the CJBs, therefore, the WCJBs showed the potential for superior protection of 225 stored grains against humid air.

226 Seed storage experiments. We investigated the potential of WCJBs to enhance the shelf-life and 227 viability of wheat grains (T. aestivum) stored at 50\%-98\% RH for 2 months by comparing their 
228 performance with that of CJBs (Fig. 1). The SMC of the wheat prior to storage was 7.1\%, which 229 was well within Harrington's safe zone $(6 \%-16 \%)^{24}$. Wheat grains were stored in WCJBs and $230 \mathrm{CJBs}$ (as controls) at $21.6^{\circ} \mathrm{C} \pm 0.5^{\circ} \mathrm{C}$ under three different air humidity conditions: $55 \%, 75 \%$, 231 and $98 \%$ RH. During the 2-month-long storage experiment, we examined the moisture 232 absorption and mold growth on jute bags and stored grains every 3 days (Fig. 5). For the 55\% $233 \mathrm{RH}$ treatment, there were no significant differences in moisture absorption between the WCJBs 234 and CJBs and the grains stored within these bags (Fig. 5A and D). Consequently, at the end of 235 the storage period, the grains had not suffered from fungal growth. Similarly, for the $75 \% \mathrm{RH}$ 236 treatment, the WCJBs and their stored grains did not exhibit moisture absorption or mold 237 growth; however, the CJBs and their stored grains showed dampness and fungal growth (Fig. 5B 238 and E). For the 98\% RH treatment, both the CJBs and WCJBs and their stored grains exhibited 239 dampness and fungal growth (Fig. 5C and F). Nevertheless, although the water droplets 240 condensed and grew on the WCJBs, they rolled off along the surface because of bags' water 241 repellence (Fig. 5F, inset); consequently, fungal proliferation on wheat grains stored in WCJBs at $24298 \% \mathrm{RH}$ was less prominent than that on wheat grains stored in CJBs. 

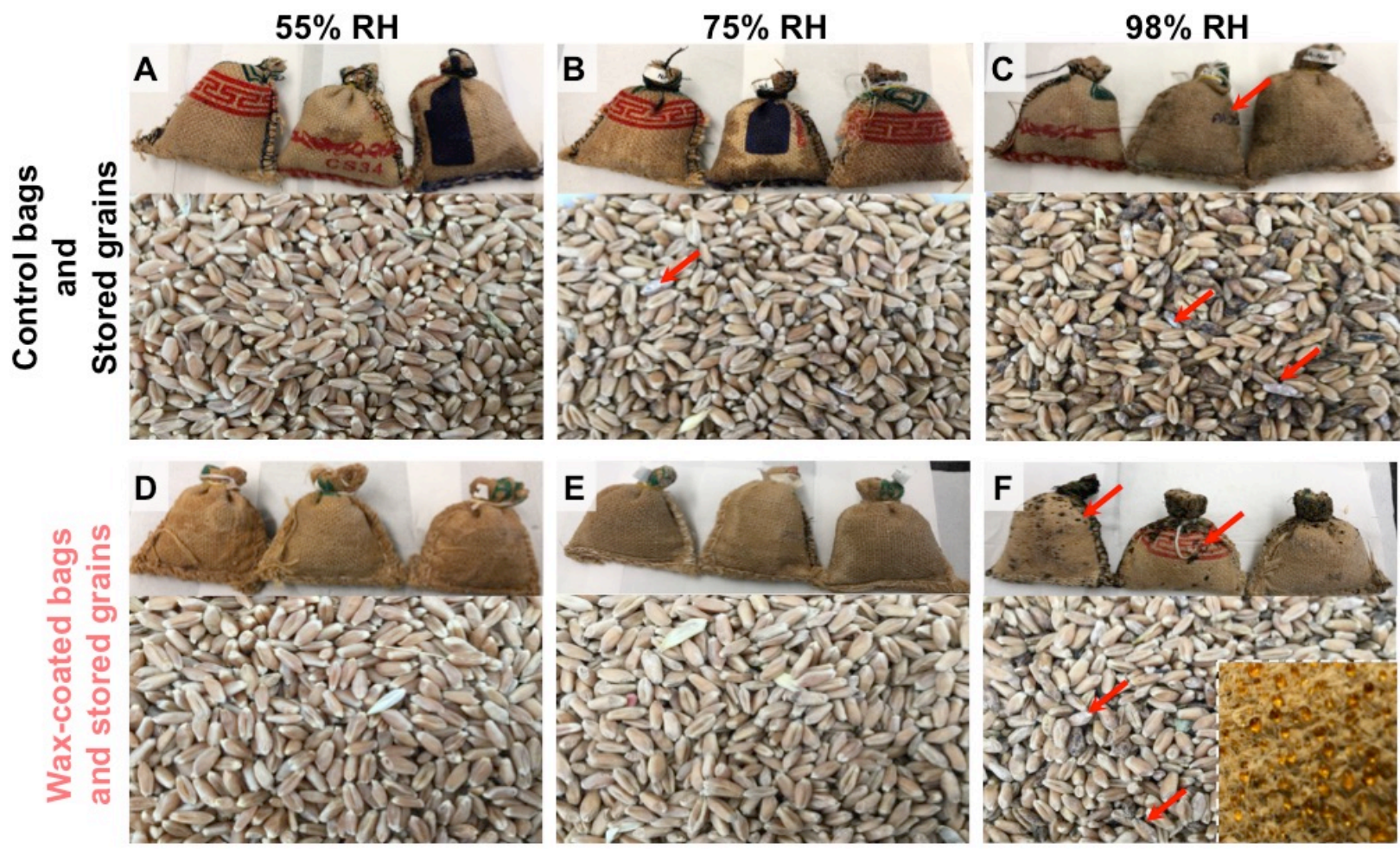

Figure 5. Photographs of wax-coated jute bags (WCJBs) and untreated control jute bags (CJBs) with stored wheat grains after 8 weeks of storage in different relative humidity $(\mathrm{RH})$ conditions. CJBs and wheat grains stored at 55\% RH (A), 75\% RH (B), and 98\% RH (C); WCJBs and wheat grains stored at 55\% RH (D), $75 \% \mathrm{RH}(\mathbf{E})$, and 98\% RH (F). Red arrows indicate fungal (mold) growth. At 55\% RH, neither WCJBs nor CJBs suffered from dampness or fungal growth, although seed moisture content increased from $7.1 \%$ to $7.5 \%$ and $14.9 \%$ in WCJBs and CJBs, respectively. WCJBs also performed well at 75\% $\mathrm{RH}$; however, grains stored in CJBs at $75 \%$ $\mathrm{RH}$ showed signs of fungal growth. At $98 \% \mathrm{RH}$, both WCJBs and CJBs and their stored grains exhibited dampness and fungal growth (dark grey patches). The inset photograph in (F) shows the accumulation of moisture on WCJBs in the third week of storage.

The amount of moisture absorbed by the bags containing stored grains and the grains' moisture absorbed through the WCJBs was 46\% lower than that absorbed through the CJBs (Fig. within Harrington's safe zone, whereas the SMC of grains in the CJBs increased to $14.9 \%$ 
261 (Figure 6B). CJBs absorbed twelve times the moisture absorbed by WCJBs; thus, they acted as reservoirs for moisture influx into stored grains. At 75\% RH, the total moisture absorbed through the WCJBs was 32\% lower than that absorbed through the CJBs; the SMC of grains stored in WCJBs increased from $7.1 \%$ to $11 \%$, whereas the SMC of grains increased to $17 \%$ in the CJBs, i.e., the latter SMC violated Harrington's rule leading to fungal infestation. At an RH of 98\%, the total moisture absorbed through the WCJBs was 45\% lower than that absorbed through the CJBs; the SMC of grains stored in WCJBs increased to $26 \%$, whereas the SMC of grains in CJBs increased to $32 \%$. Thus, at $95 \% \mathrm{RH}$, both storage media failed to safeguard grains. Notwithstanding, significant differences were found between WCJBs and CJBs for both total moisture absorbed and $\operatorname{SMC}(p<0.05)$ at all RHs.

271
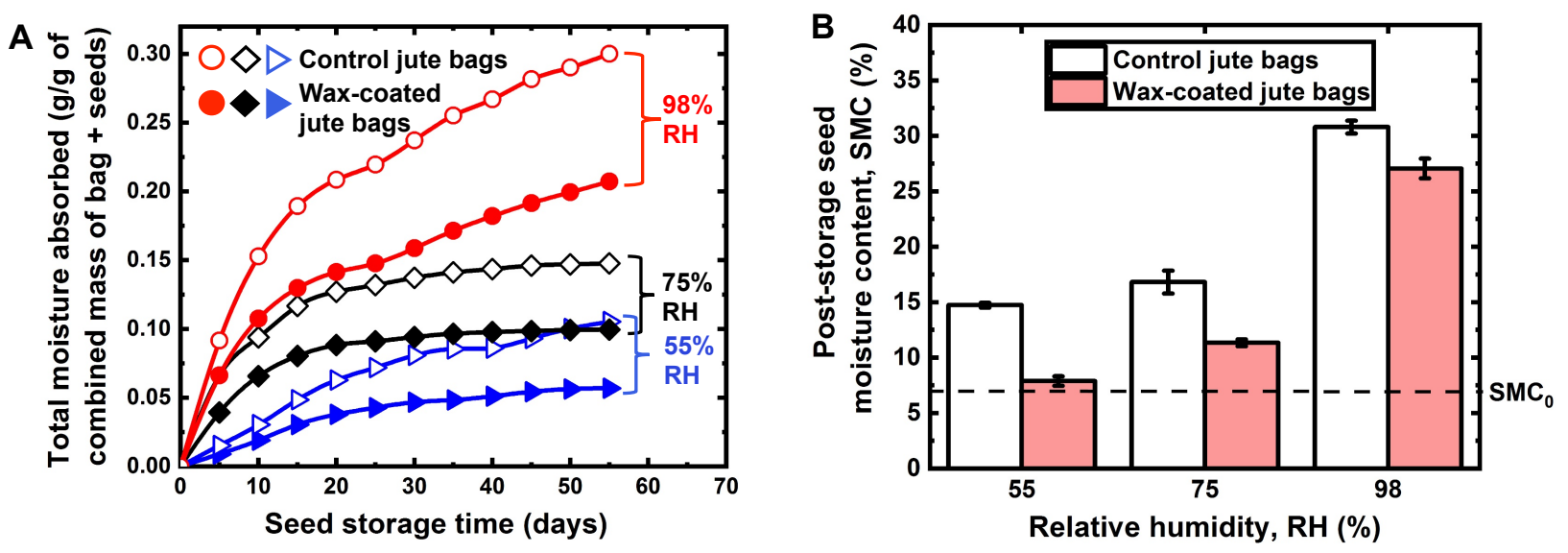

Figure 6. Moisture absorption through jute bags and the moisture content of wheat grains after 2 months of storage. (A) Total moisture absorbed through control jute bags (CJBs: unfilled shapes) and wax-coated jute bags (WCJBs: filled shapes) over the seed-storage period. Total moisture absorbed was taken as the sum of moisture uptake by jute bags and stored grains; the average combined mass of the storage bag plus seed was $\sim 170 \mathrm{~g} / \mathrm{bag}$. (B) Post-storage seed moisture content (SMC) of stored wheat grains at different relative humidity (RH) conditions. Horizontally-dotted line $\left(\mathbf{S M C}_{\mathbf{0}}\right)$ represents initial SMC (7.1\%) before storage; error bars represent the standard errors $( \pm \mathrm{SE})$ of means from three replicates. 
Seed viability after storage. The germination capacity of seeds, or seed viability, is affected by

283

284

285

286

287

288

289

290

291

292

293

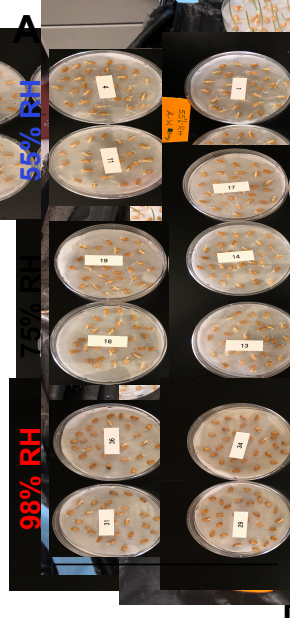
respectively (Fig. 7). increasing SMC and fungal molds ${ }^{29}$. For example, the germination capacity of soybean (Glycine max), sorghum (Sorghum bicolor), red clover (Trifolium pratense), and Timothy grass (Phleum pratense) seeds reduces substantially during 6-12 months of storage at $30^{\circ} \mathrm{C}$ and $75 \% \mathrm{RH}^{29}$. To investigate the full potential of WCJBs as a reliable seed storage medium, we studied the germination of the stored grains using the following formula: $S G=\frac{\text { Number of germinated seeds }}{\text { Total number of seeds sown }} \times$ $100 \%$. Overall, we found that germination was significantly higher for wheat grains stored in WCJBs than for wheat grains stored in CJBs $(p<0.05)$. Specifically, at 55\%, 75\%, and $98 \%$ $\mathrm{RH}$, storage in WCJBs resulted in $32 \%, 35 \%$, and $12 \%$ improved germination capacity,

Figure 7. Seed germination on Petri dishes of wheat grains stored for 8 weeks in control jute bags and wax-coated jute bags (WCJBs) at different relative humidity (RH) conditions. (A) Seed germination patterns monitored for 7 days after sowing and (B) seed germination of seeds stored in control jute bags and WCJBs at 55\%, 75\%, and 98\% RH. The percentage seed germination of wheat grains stored in WCJBs was higher than that of wheat grains stored in control bags under

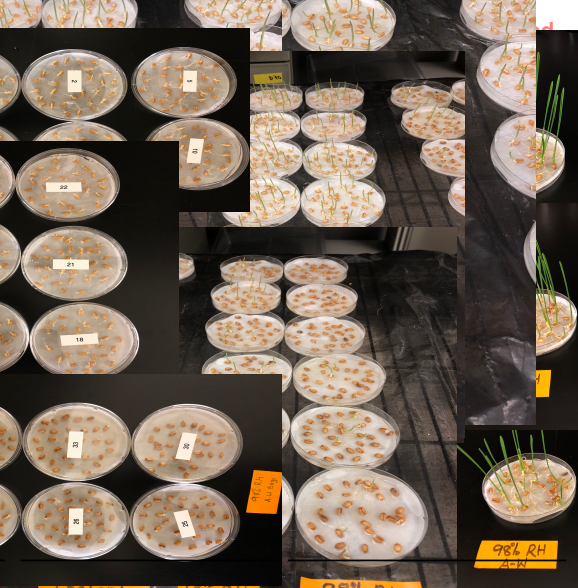

Days after sowing

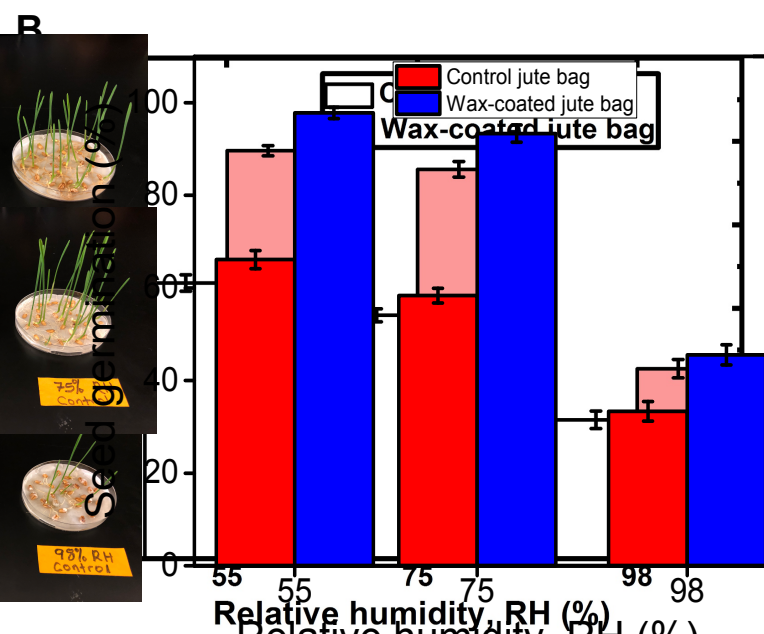

300 
Taken together, our results demonstrate the efficacy of WCJBs. This bioinspired engineering solution can enhance the shelf-life of grains by maintaining their SMC within the limits of Harrington's safe zone. In Fig. 8, we illustrate the comparative seed storage potential of

304 CJBs and WCJBs. Naturally, a question arises: what are the factors and mechanisms that 305 underlie the superior performance of WJCBs over CJBs? Firstly, the water repellence of WCJBs 306 reduces the accumulation of water from precipitation or condensation because drops of certain 307 momentum and mass roll off the enhanced bags; with fewer sessile drops on a porous surface, 308 absorption and mass transfer are also reduced. Secondly, we noticed that the fibers of WCJBs 309 were somewhat swollen in contrast to those of CJBs (Fig. 4). This likely led to partial pore 310 clogging of the treated-jute layer and reduced the flux of water vapor through the pores. In 311 addition, enhanced surface roughness due to the removal of surface impurities and other fiber 312 components by alkali could have increased the contact area between the jute fibers and wax 313 matrix $^{60}$. Consequently, paraffin wax seeping through pores from both surfaces could eventually 314 clog some pores. This hypothesis is consistent with the findings of Ghosh et al. ${ }^{62}$, who studied 315 the durability of jute geotextiles in soil; they noticed that impregnation of nonwoven jute samples 316 with bitumen reduced jute pore sizes because of the formation of a superimposing bitumen 317 binder layer on the surface of both sides of the jute fabric. Additional studies on the efficacy of 318 this approach, in which different seed types, storage durations, and temperatures are applied, as 319 well as on the exposure of WCJBs to running water (time-dependent changes in wetting) ${ }^{60}$, are 320 required to explore strengths and weaknesses of this approach. The mechanical strength of 321 WCJBs also needs to be compared against CJBs to ensure that they will not start physically 322 deteriorating after loading. 


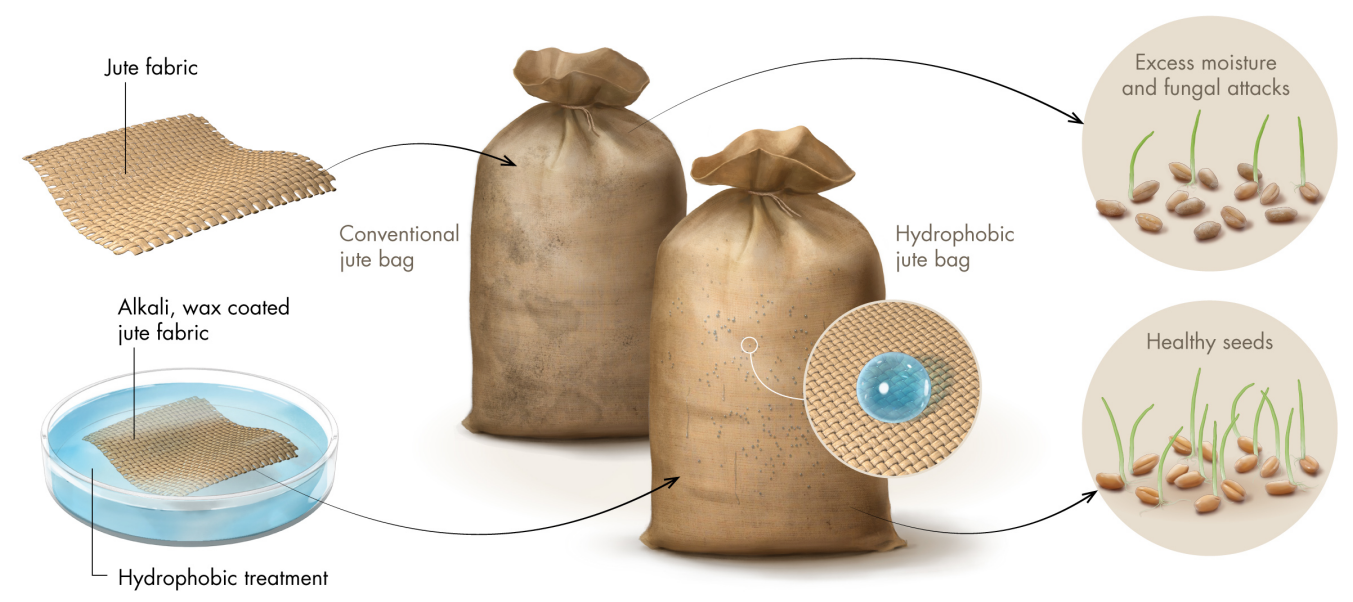

Figure 8. Schematic showing the surface treatments of jute bags with alkali and wax coating, the seed storage experiment, and the germination experiment for stored wheat grains. Conventional (control) jute bag, CJB; hydrophobic (wax-coated) jute bag, WCJB. On the WCJB, water droplets accumulate and roll off the surface. Seeds from hydrophobic jute bags are more likely to germinate than seeds from conventional jute bags. Credit: Xavier Pita, KAUST.

In summary, WCJBs have the potential to alleviate PHLs due to seed deterioration in regions with a humid climate, e.g., the Indian subcontinent and sub-Saharan Africa. Farmers in these regions extensively exploit conventional jute bags to store grains; these bags are stacked in traditional storage structures or outdoor stockpiles covered with tarpaulin ${ }^{9,19}$. Thus, the stored

334 grains are often exposed to high humidity, especially in the event of precipitation or increased $\mathrm{RH}$, which elevates SMC, accelerates the deterioration of seeds, and reduces germination capacity. In the present study, wheat grains stored in WCJBs for over 2 months experienced small deviations in SMC, i.e., 7.1\%-7.5\% at 55\% RH and $7.1 \%-11 \%$ at $75 \% \mathrm{RH}$ that were well within Harrington's limits. In contrast, wheat grains stored in CJBs over the same duration experienced much higher SMC, i.e., 7.1\%-14.9\% at 55\% RH and 7.1\%-17\% at 75\% RH.

340 Consequently, WCJBs improved the germination capacity of stored grains by $32 \%-35 \%$ in 341 comparison with the germination capacity of grains stored in CJBs under identical conditions. 
342 Therefore, WCJBs have the potential to substantially extend the shelf-life of seeds under low RH

343 conditions and they facilitate increased resilience under higher RH conditions. Importantly,

344 grains stored in WCJBs remain within Harrington's safe zone for SMC; thus, PHLs due to seed

345 deterioration are prevented. The low cost, eco-friendliness, and availability of jute fabrics,

346 alkalis, and paraffin wax, along with the simplicity of the treatment process, gives wax-coated

347 jute fabrics great potential for use in agro-technologies and other applications.

349 Abbreviations used: PHL: post-harvest losses; CJBs: control jute bags; WCJBs: wax-coated 350 jute bags; SMC: seed moisture content; RH: relative humidity.

352 Acknowledgements: The coauthors thank Mr. Sankara Arunachalam (KAUST) for his 353 assistance with the scanning electron microscopy of jute bags; Mr. Xavier Pita, Senior Scientific

354 illustrator, KAUST, for creating the graphical abstract and Figs. 2 and 8; Dr. Nishan MA for 355 sourcing and preparing the jute bags; Mrs. Juliet Aber for sewing the jute bags used in the seed 356 storage experiment; Prof. Magdi Mousa of the King Abdulaziz University, Jeddah, for providing 357 the wheat grains used in this study; and Mr. Firas Atef Baba (KAUST) for providing the jute 358 bags.

360 Conflict of interest: $\mathrm{HM}$ and $\mathrm{KO}$ have filed a provisional patent (USPTO Serial No. $361 \mathbf{6 3 / 1 4 1 , 1 0 4 )}$. 
363 Author contributions: HM conceived the idea and led this research project. KO designed and 364 performed the experiments, including the surface treatments and materials characterization, seed 365 storage study, and germination study. AGJ assisted with the experimental design, data analysis, 366 and the wetting model. KO wrote the manuscript, which HM and AGJ revised.

368 Funding source: The research reported in this publication was supported by funding from King 369 Abdullah University of Science and Technology under award number BAS/1/1070-01-01.

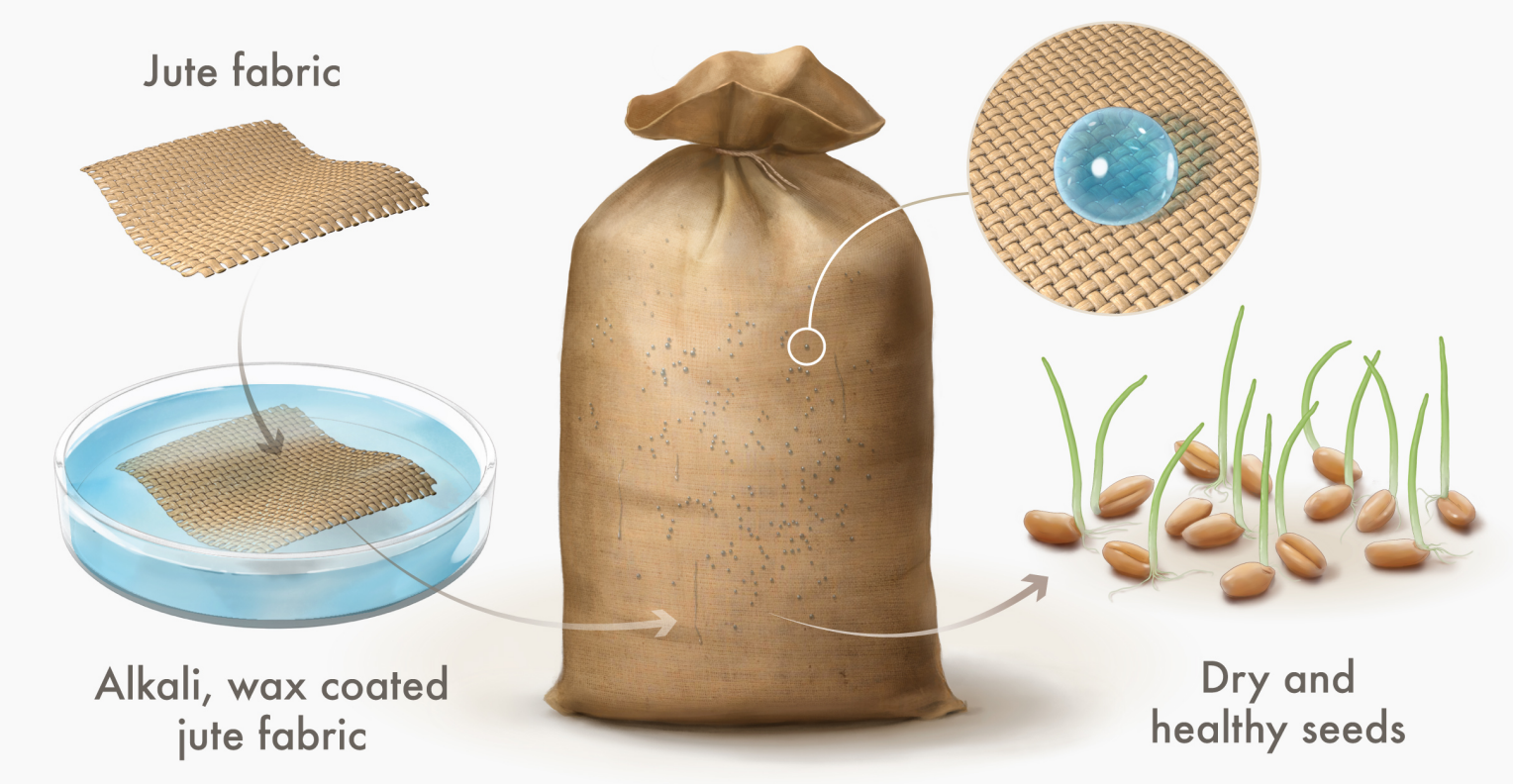

374 Synopsis. This paper broadens the utilization of paraffin wax, a benign bi-product of petroleum, to engineer hydrophobic seed storage jute bags. 
379 1. World-Food-Programme, Hunger, Conflict, and Improving the Prospects for Peace. United Nations World Food Programme: Rome, Italy, October 2020.

2. United-Nations World Population Prospects: The 2017 Revision; United Nations, Department of Economic and Social Affairs, Population Division: New York, NY, USA, 2017.

3. Alexandratos, N.; Bruinsma, J. World Agriculture Towards 2030/2050: The 2012 Revision ESA Working paper No. 12-03. Rome, FAO.; FAO: Rome, 2012.

4. FAO The future of food and agriculture: Trends and challenges; Food and Agriculture Organization of the United Nations 2017.

5. FAO Global agriculture towards 2050; Food and Agriculture Organization: Rome, 2009; pp 1-4.

6. FAO Global food losses and food waste: extent, causes and prevention; Food and Agriculture Organization: Rome, 2011; p 37.

7. Gustavsson, J. C., C.; Sonesson, U.; and Emanuelsson, A The methodology of the FAO study: "Global Food Losses and Food Waste - extent, causes and prevention"- FAO, 2011; 2013.

8. Mesterhazy, A.; Olah, J.; Popp, J., Losses in the Grain Supply Chain: Causes and Solutions. Sustainability 2020, 12 (6).

9. Jayas, D. S., Storing Grains for Food Security and Sustainability. Agricultural Research 2012, 1, 21-24.

10. Lal, R., Feeding 11 billion on 0.5 billion hectare of area under cereal crops. Food and Energy Security 2016, 5 (4), 239-251.

11. Rodell, M.; Velicogna, I.; Famiglietti, J. S., Satellite-based estimates of groundwater depletion in India. Nature 2009, 460 (7258), 999-U80.

12. Solander, K. C.; Reager, J. T.; Wada, Y.; Famiglietti, J. S.; Middleton, R. S., GRACE satellite observations reveal the severity of recent water over-consumption in the United States. Scientific Reports 2017, 7.

13. Scanlon, B. R.; Longuevergne, L.; Long, D., Ground referencing GRACE satellite estimates of groundwater storage changes in the California Central Valley, USA. Water Resources Research 2012, 48.

14. Famiglietti, J. S., The global groundwater crisis. Nature Climate Change 2014, 4 (11), 945-948.

15. FAO Seeds toolkit; Rome, 2018; p 112 pp.

16. Sawicka, B., Post-harvest Losses of Agricultural Produce BT - Zero Hunger. Leal Filho, W.; Azul, A. M.; Brandli, L.; Özuyar, P. G.; Wall, T., Eds. Springer International Publishing: Cham, 2019; pp 1-16.

17. DE LUCIA, M. A., D Agricultural Engineering in Development: Post-harvest Operations and Management of Foodgrains; FAO Agricultural Services

: Rome 1994.

18. Hodges, R. J.; Buzby, J. C.; Bennett, B., Postharvest losses and waste in developed and less developed countries: opportunities to improve resource use. Journal of Agricultural Science 2011, 149, 37-45.

19. Tesfaye, W.; Tirivayi, N., The impacts of postharvest storage innovations on food security and welfare in Ethiopia. Food Policy 2018, 75 (February), 52-67. 
20. Kumar, D.; Kalita, P., Reducing Postharvest Losses during Storage of Grain Crops to Strengthen Food Security in Developing Countries. Foods 2017, 6 (1), 8-8.

21. Boxall, R. A., Post harvest losses to insects-A world view. International Biodeterioration and Biodegradation 2001; Vol. 48, pp 137-152.

22. Kumar, R.; Mishra, A. K.; Dubey, N. K.; Tripathi, Y. B., Evaluation of Chenopodium ambrosioides oil as a potential source of antifungal, antiaflatoxigenic and antioxidant activity. International Journal of Food Microbiology 2007, 115 (2), 159-164.

23. Harrington, J. F., Seed storage and longevity. . In Seed Biology, Kozlowski, T. T., Ed. Academic Press: New York \& London, 1972; Vol. III.

24. Harrington, J. F., Biochemical basis of seed longevity

. Seed Sci. Technol. 1973, 1, 453-461.

25. Gupta, M. K.; Srivastava, R. K.; Bisaria, H., Potential of Jute Fibre Reinforced Polymer Composites : A Review. International Journal of Fiber and Textile Research 2015, 5 (3), 30-38.

26. Wang, W.-m.; Cai, Z.-s.; Yu, J.-y., Study on the Chemical Modification Process of Jute Fiber. Journal of Engineered Fibers and Fabrics 2008, 3 (2), 155892500800300203.

27. Mwaikambo, L. Y.; Ansell, M. P., Chemical modification of hemp, sisal, jute, and kapok fibers by alkalization. Journal of Applied Polymer Science 2002, 84 (12), 2222-2234.

28. Ali, A.; Shaker, K.; Nawab, Y.; Jabbar, M.; Hussain, T.; Militky, J.; Baheti, V., Hydrophobic treatment of natural fibers and their composites-A review. Journal of Industrial Textiles 2018, 47 (8), 2153-2183.

29. Delouche JC, M. R., Dougherty GM, Boyd AH, Storage of seed in Sub-tropical and Tropical regions. Seed Science and Technology 1973, 1, 671-700.

30. Bradford, K. J.; Dahal, P.; Asbrouck, J. V.; Kunusoth, K.; Bello, P.; Thompson, J.; Wu, F., The dry chain : Reducing postharvest losses and improving food safety in humid climates. Trends in Food Science \& Technology 2018, 71 (November 2017), 84-93.

31. Manandhar, A.; Milindi, P.; Shah, A., An Overview of the Post-Harvest Grain Storage Practices of Smallholder Farmers in Developing Countries. Agriculture 2018, 8 (4), 57.

32. Nagpal, M.; Kumar, A., Grain losses in India and government policies. Quality Assurance and Safety of Crops \& Foods 2012, 4 (3), 143-143.

33. Swai, J., Mbega, E. R., Mushongi, A., \& Ndakidemi, P. A., Post-harvest losses in maize store-time and marketing model perspectives in Sub-Saharan Africa. Journal of Stored Products and Postharvest Research 2019, 10 (1), 1-12.

34. Barthlott, W.; Neinhuis, C., Purity of the sacred lotus, or escape from contamination in biological surfaces. Planta 1997, 202 (1), 1-8.

35. Mahadik, G. A.; Hernandez-Sanchez, J. F.; Arunachalam, S.; Gallo, A.; Cheng, L.; Farinha, A. S.; Thoroddsen, S. T.; Mishra, H.; Duarte, C. M., Superhydrophobicity and size reduction enabled Halobates (Insecta: Heteroptera, Gerridae) to colonize the open ocean. Scientific Reports 2020, 10 (1).

36. Cheng, L., Marine and Freshwater Skaters: Differences in Surface Fine Structures. Nature 1973, 242 (5393), 132-133.

37. Domingues, E. M.; Arunachalam, S.; Mishra, H., Doubly Reentrant Cavities Prevent Catastrophic Wetting Transitions on Intrinsically Wetting Surfaces. Acs Applied Materials \& Interfaces 2017, 9 (25), 21532-21538.

38. Pan, Z.; Pitt, W. G.; Zhang, Y.; Wu, N.; Tao, Y.; Truscott, T. T., The upside-down water collection system of Syntrichia caninervis. Nature Plants 2016, 2 (7), 16076. 
39. Parker, A. R.; Lawrence, C. R., Water capture by a desert beetle. Nature 2001, 414 (6859), 33-34.

40. Darmanin, T.; Guittard, F., Superhydrophobic and superoleophobic properties in nature. Materials Today 2015, 18 (5), 273-285.

41. Wong, T. S.; Kang, S. H.; Tang, S. K. Y.; Smythe, E. J.; Hatton, B. D.; Grinthal, A.; Aizenberg, J., Bioinspired self-repairing slippery surfaces with pressure-stable omniphobicity. Nature 2011, 477 (7365), 443-447. 42. Arunachalam, S.; Das, R.; Nauruzbayeva, J.; Domingues, E. M.; Mishra, H., Assessing omniphobicity by immersion. Journal of Colloid and Interface Science 2019, 534, 156-162.

43. Subramanian, N.; Qamar, A.; Alsaadi, A.; Gallo, A.; Ridwan, M. G.; Lee, J.-G.; Pillai, S.; Arunachalam, S.; Anjum, D.; Sharipov, F.; Ghaffour, N.; Mishra, H., Evaluating the potential of superhydrophobic nanoporous alumina membranes for direct contact membrane distillation. Journal of Colloid and Interface Science 2019, 533, 723-732.

44. Gonzalez-Avila, S. R.; Nguyen, D. M.; Arunachalam, S.; Domingues, E. M.; Mishra, H.; Ohl, C.-D., Mitigating cavitation erosion using biomimetic gas-entrapping microtextured surfaces (GEMS). Science Advances 2020, 6 (13), eaax6192. 45. Das, R.; Ahmad, Z.; Nauruzbayeva, J.; Mishra, H., Biomimetic Coating-free Superomniphobicity. Scientific Reports 2020, 10 (1), 7934.

46. Chauhan, P.; Kumar, A.; Bhushan, B., Self-cleaning, stain-resistant and anti-bacterial superhydrophobic cotton fabric prepared by simple immersion technique. J Colloid Interface Sci 2019, 535, 66-74.

47. Vermeulen, S. J.; Campbell, B. M.; Ingram, J. S. I., Climate Change and Food Systems. Annual Review of Environment and Resources 2012, 37 (1), 195-222.

48. Jury, W. A.; Vaux, H., The role of science in solving the world's emerging water problems. Proceedings of the National Academy of Sciences of the United States of America 2005, 102 (44), 15715-15720.

49. Wexler, A.; Hasegawa, S., Relative Humidity-Temperature Relationships of Some Saturated Salt Solutions in the Temperature Range 0-Degree to 50-Degrees-C. Journal of Research of the National Bureau of Standards 1954, 53 (1), 19-26.

50. Suma, A.; Sreenivasan, K.; Singh, A. K.; Radhamani, J., Role of Relative Humidity in Processing and Storage of Seeds and Assessment of Variability in Storage Behaviour in Brassica spp. and Eruca sativa. Scientific World Journal 2013.

51. Origin(Pro) OriginLab Corporation: Northampton, MA, USA, Version 2017.

52. Ray, D.; Sarkar, B. K.; Rana, A. K.; Bose, N. R., Effect of alkali treated jute fibres on composite properties. Bulletin of Materials Science 2001, 24 (2), 129-135.

53. Bhushan, B., Biomimetics: lessons from nature--an overview. Philos Trans A Math Phys Eng Sci 2009, 367 (1893), 1445-86.

54. Gassan, J.; Bledzki, A. K., Possibilities for improving the mechanical properties of jute/epoxy composites by alkali treatment of fibres. Composites Science and Technology 1999, 59 (9), 1303-1309.

55. Taha, I.; Steuernagel, L.; Ziegmann, G., Optimization of the alkali treatment process of date palm fibres for polymeric composites. Composite Interfaces 2007, 14 (7-9), 669-684.

56. Kuruvilla, J.; Sabu, T.; Pavithran, C.; Brahmakumar, M., Tensile properties of short sisal fiber-reinforced polyethylene composites. Journal of Applied Polymer Science 1993, 47 (10), 511 1731-1739. 
512 57. Chen, H.; Yu, Y.; Zhong, T. H.; Wu, Y.; Li, Y. J.; Wu, Z. H.; Fei, B. H., Effect of alkali 513 treatment on microstructure and mechanical properties of individual bamboo fibers. Cellulose $514 \quad 2017,24(1), 333-347$.

515 58. Wang, X.; Chang, L. L.; Shi, X. L.; Wang, L. H., Effect of Hot-Alkali Treatment on the 516 Structure Composition of Jute Fabrics and Mechanical Properties of Laminated Composites. 517 Materials 2019, 12 (9).

518 59. Castro, G. R.; Panilaitis, B.; Kaplan, D. L., Emulsan, a tailorable biopolymer for 519 controlled release. Bioresour Technol 2008, 99 (11), 4566-71.

$520 \quad 60 . \quad$ Mishra, H.; Schrader, A. M.; Lee, D. W.; Gallo, A.; Chen, S. Y.; Kaufman, Y.; Das, S.; 521 Israelachvili, J. N., Time-Dependent Wetting Behavior of PDMS Surfaces with Bioinspired, 522 Hierarchical Structures. Acs Applied Materials \& Interfaces 2016, 8 (12), 8168-8174.

523 61. Cassie, A. B. D.; Baxter, S., Wettability of porous surfaces. Transactions of the Faraday 524 Society 1944, 40, 0546-0550.

525 62. Ghosh, S. K.; Ray Gupta, K.; Bhattacharyya, R.; Sahu, R. B.; Mandol, S., Improvement 526 of Life Expectancy of Jute Based Needlepunched Geotextiles Through Bitumen Treatment. 527 Journal of The Institution of Engineers (India): Series E 2014, 95 (2), 111-121. 